\title{
Day lighting and thermal analysis using various double reflective window glasses for green energy buildings
}

\author{
Kiran K. Gorantla ${ }^{1}$, Saboor Shaik ${ }^{2 *}$, Ashok B.T.P.R. Setty ${ }^{1}$ \\ ${ }^{1}$ Mechanical Engineering Department, National Institute of Technology Karnataka, Surathkal, Mangalore 575025, \\ Karnataka, India \\ ${ }^{2}$ Department of Thermal and Energy, VIT University, Vellore 632014, Tamilnadu, India
}

Corresponding Author Email: saboor.nitk@gmail.com

https://doi.org/10.18280/ijht.360345

Received: 6 March 2018

Accepted: 13 August 2018

\section{Keywords:}

spectral characteristics, visible optical properties, solar optical properties and double gold reflective glass window

\begin{abstract}
The objective of this research work is to identify the best double reflective window glass which provides adequate daylighting by controlling solar heat gain as per the requirement of summer and winter seasons of composite climatic zone in India. To attain this objective an investigation of spectral characteristics of different reflective glasses such like gold, sapphire blue, opal blue, grey, green and bronze reflective glasses is carried out experimentally using Shimadzu UV 3600 spectrophotometer in the entire solar spectrum wavelength range from $300 \mathrm{~nm}$ to $2500 \mathrm{~nm}$ based on ASTM E 424 standards. The measured spectral characteristics were used to compute the visible optical properties in the visible zone and solar optical properties in solar spectrum zone by using International standard method with a MATLAB code. The computed optical properties transmittance, reflectance and absorbance are used in the simulation tool for heat gain and daylight calculations for a school room building. As far as both hottest and coolest days are concerned double gold reflective window glass (DGLDRGW) is found to be the best in the South orientation. During hottest day, DGLDRGW gains minimum heat of $2.13 \mathrm{kWh}$ with adequate daylight factor $(2.049 \%$ at 9 A.M. and $2.025 \%$ at 4 P.M.) and also it gains maximum heat of $8.55 \mathrm{kWh}$ with adequate daylight factor $(2.729 \%$ at 9 A.M. and $2.732 \%$ at 4 P.M.) for school room building among six studied double reflective window glasses.
\end{abstract}

\section{INTRODUCTION}

Buildings consume around $40 \%$ of energy to provide thermal comfort and day lighting into buildings. Growing countries like America, Russia, China and India are consuming maximum energy. In India, buildings are reported to consume $33 \%$ of the energy for heating and cooling loads and also, visual comfort for both commercial and residential buildings as per GRIHA data. Most of the buildings today are comprised of different glasses which cover maximum area of buildings. Generally clear glass is widely used in modern buildings to ensure proper day lighting into buildings. Solar radiation enters quickly through glass windows in comparison to walls, roof and floor and also, more radiation passes through it as it is transparent. The most important properties of any glass are transmittance, reflectance and absorbance. These properties vary with respect to physical and chemical properties of window glasses. Position or location of windows location also plays a significant role in increasing or decreasing incoming solar radiation into buildings. Extensive use of glass enclosures such as clear glass gains more amount of heat gain and more day lighting into the buildings resulting in uncomfortable conditions. This limitation can be tackled by addition of metal oxides into molten glass to tint clear glasses. The variations in the tint can be achieved by varying the type of metal oxides. For instance, oxides of iron, manganese, chromium, and vanadium are responsible for colored tint in the glass. These colored tinted glasses are capable of reducing the cooling loads by blocking some of the solar energy and by diminishing energy transmission. Apart from mixing of metals while making the glass, metal coatings can also be applied on the surface of the glasses in order to increase the light reflection. These glasses are dayed as reflective glasses. Coating a thin film of metals on glasses (e.g., gold, silver, copper and aluminum) display exciting effect on controlling the optical properties of window glasses.

Earlier authors worked on different window glasses like clear, bronze with double and triple glazing with an air gap of $10 \mathrm{~mm}$ to find the minimum solar radiation passing through it [1]. Study of various glass windows like clear, bronze, green and bronze-reflective glass windows to keep the window inclined towards the earth to minimize the direct solar radiation from all locations to Indian latitudes was reported [2]. Minimization of solar radiation through clear and bronze window glass materials to keep inward inclination 150 to window to Bagdad city latitude was studied in detail [3]. Analysis of decrease in energy consumption by various exterior envelopes like double clear, double low-E glasses to office buildings in hot climatic zone Saudi Arabia was done by using design builder simulation tool [4]. Investigation of different window glasses and building materials was carried out to find the heat gain through all parts of building in Mangalore (Warm \& humid climatic zone) latitude by maintaining different window to wall ratios from south location [5]. Different low-E glasses like single, double low-E to keep the buildings as a window to save the energy annually 
in central southern zone of South Korea was studied [6].

Low-E glass was compared with hallow low-E glass on using for windows in office buildings in Shanghai city to improve annual energy savings [7]. Retrofit strategy method was proposed for improving energy efficiency in educational buildings which is located in hot and arid climatic zone (Egypt) by carefully considering various parameters such as wall insulation, solar shading and air tightness and attained energy efficiency of 33\% [8]. Different window to wall ratios were analysed in Famagusta city to find the thermal comfort to occupants and the percentage of dissatisfied and predicted mean vote values were analyze and optimized [9]. Energy consumption by buildings was decreased by keeping a window in each location at different sizes at 65 different scenarios by using Autodesk Green Building Studio tool [10]. Visible properties of six tinted and reflective window glasses were measured experimentally and these properties were used to find the daylight factor in buildings to warm \& humid climatic zone of India [11]. Studies on maximizing the natural day light and reducing the artificial energy consumption of SODHA BERS COMPLEX building which is located in Varanasi was carried out by considering parameters such as energy payback time, energy production factor and life cycle conversion efficiency and reported energy saving up to $3675.61 \mathrm{kWh}$ [12].

The performance of hollow and Low-E glass windows of optimum size at various window to wall ratios in different climatic zones of cities Chongqing, Shanghai, and Wuhan of China country were evaluated and compared by using designer's simulation tool kit and the annual heating energy, annual cooling energy and total energy consumption annually was described in detail [13]. Daylight factor model was developed and it was validated experimentally for east oriented windows with clear glass at clear and intermediate sky conditions to the SODHA BERS COMPLEX which is located in Varanasi [14]. Numerical methodology simulation was developed to dedayine day lighting in to an office building by keeping double glazed window with highly reflective blinds and varying blind tilt angle to provide necessary day lighting in buildings [15]. Examined different types of external shading devices on bronze glass window to find optimum heat gain and day lighting in reading room buildings for hot and dry climatic zone in India [16]. Implementation of analytical and useful methods using thermal analysis simulation software for residential buildings which is situated in New Assiut City, Egypt which is having horizontal shading device on windows. The results found by these methods are suitable especially for hot dessert areas [17]. Direct and diffuse sky elements were considered to find the day light performance of an atrium space. A new daylight performance metric was used and it was compared with experimental results [18].

Natural day lighting through skylight illuminance inside a dome shaped adobe house was studied at three different surface levels by considering hourly inside and outside illuminance data of each month in New Delhi climatic region to reduce artificial energy consumption at different sky illuminance conditions [19]. University building constructed in Hong Kong used two methods two methods namely nomographs and waldram diagrams to find indoor daylight illuminance. [20]. The RADIANCE simulation tool was used to determine vertical daylight illuminance of buildings in nonovercast sky conditions with a clear glass window [21]. A double clear glass window was used for the analysis of illuminance level on the floor of a room from window. Two daylight algorithms available in Energy Plus software such as
Delight and detailed methods were used for the analysis. The algortithm results have been compared with the experimentl values and reported in the literature [22]. Reduce energy consumption in buildings using various solar control glasses used as windows for buildings carried out in three different climatic zones was reported [23]. Studies on reducing heat gain through various double float and tint glasses of buildings in Indian hot and dry climatic zones were reported [24].

The above literature shows the significant gap for research on solar control double reflective glasses for thermal and visual comfort studies. The present work uses six reflective glasses such as gold, sapphire blue, opal blue, grey, green, and bronze-reflective to identify the best double pane window glass for reduced cooling loads and reduced energy consumption for artificial daylighting [33]. Double pane reflective glasses with an air gap of $10 \mathrm{~mm}$ were placed in different locations of a class room building for thermal and visual comfort studies. These studies were carried out on hottest and coolest days of composite climatic zone in India.

\section{MATERIALS AND METHODS}

\subsection{Materials}

In this paper, thermal and visual performance of double pane windows with six types of commercial glasses (reflective) was evaluated mathematically. The six reflective glass samples (i.e., gold, sapphire blue, opal blue, grey, green and bronze-reflective). The size of the glass samples is $30 \times$ $30 \mathrm{~mm}$ with $5 \mathrm{~mm}$ thickness.

\subsection{Method for evaluating the visible and solar optical properties of glasses}

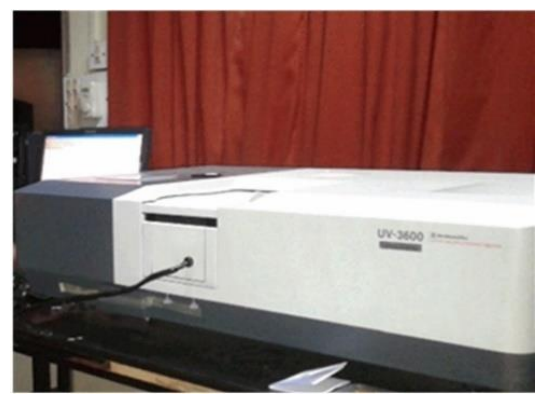

Figure 1. UV-3600 Shimadzu spectrophotometer with interfaced UV-Win lab software

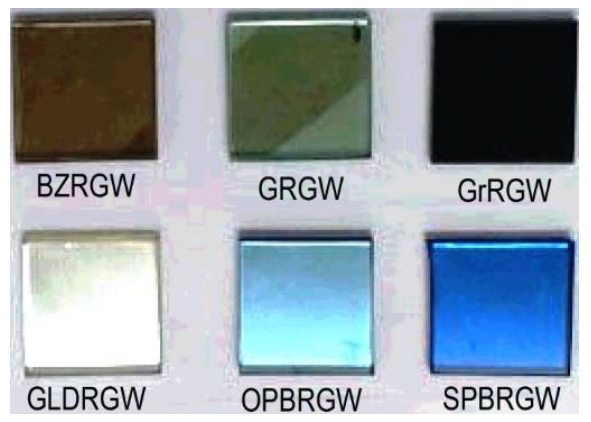

Figure 2. Images of glasses

Visible and solar optical properties of glass windows can be found by weighted average of experimental measured spectral characteristics of glass windows by using UV-3600 Shimadzu 
spectrophotometer. It is used an instrument to measure the spectral characteristics of glasses in the visible wavelength range i.e. from $380 \mathrm{~nm}$ to $780 \mathrm{~nm}$ and solar optical properties in the entire solar spectrum wavelength range from $300 \mathrm{~nm}$ to $2500 \mathrm{~nm}$. In this work to measure the spectral characteristics of clear glass and six reflective glasses such as bronze, green, grey, opal blue, sapphire blue, and gold-reflective glasses of size $30 \mathrm{~mm} \times 30 \mathrm{~mm} \times 5 \mathrm{~mm}$ at normal angle of incidence in total solar spectrum wavelength zone like transmission in specular transmission mode and reflection in diffuse reflectance mode at each wavelength interval $2 \mathrm{~nm}$ for better accuracy to get solar optical properties with an integrated 150 mm sphere based on an American standards [25]. Fig. 1 shows the UV-3600 Shimadzu spectrophotometer interfaced with PC UV-Win lab software. Fig. 2 shows the images of the glasses.

Daylight factor is defined as the ratio of inside illumination to outside illumination available in outside the building. Units of day light factor is in (\%) or in (Lux).

$\mathrm{DF}=\frac{\mathrm{E}_{\mathrm{i}}}{\mathrm{E}_{\mathrm{o}}} \times 100 \%$

Fig. 3 and Fig. 4 and illustrates the spectral transmission and reflection of six reflective glasses in ultra violet and visible wavelength zone. A MATLAB code was developed to find the weighted average of measured spectral curves which are obtained from experiments, visible properties like transmittance and reflectance of all glasses in visible wavelength range from $380 \mathrm{~nm}$ to $780 \mathrm{~nm}$ by using ISO standards [26-28], with the following equations (1) to (3).

$\mathrm{T}_{\mathrm{VIS}}=\frac{\sum_{\lambda=380 \mathrm{~nm}}^{\lambda=780 \mathrm{~nm}} \mathrm{D}_{\lambda} \tau(\lambda) \mathrm{V}(\lambda) \Delta \lambda}{\sum_{\lambda=380 \mathrm{~nm}}^{\lambda=780 \mathrm{~nm}} \mathrm{D}_{\lambda} \mathrm{V}(\lambda) \Delta \lambda}$

$\mathrm{R}_{\mathrm{VIS}}=\frac{\sum_{\lambda=380 \mathrm{~nm}}^{\lambda=780 \mathrm{~nm}} \mathrm{D}_{\lambda} \rho(\lambda) \mathrm{V}(\lambda) \Delta \lambda}{\sum_{\lambda=380 \mathrm{~nm}}^{\lambda=78 \mathrm{~nm}} \mathrm{D}_{\lambda} \mathrm{V}(\lambda) \Delta \lambda}$

Visible absorbance of the window glass in visible zone can be found by this correlation.

$\mathrm{A}_{\mathrm{VIS}}=100-\mathrm{T}_{\mathrm{VIS}}-\mathrm{R}_{\mathrm{VIS}}$

The above visible properties are useful to find the day lighting into buildings and these values are listed in Table 1.

Table 1. Visible optical properties of reflective glasses of thickness $5 \mathrm{~mm}$

\begin{tabular}{cccc}
\hline & \multicolumn{3}{c}{ Visible optical properties } \\
\hline Window glass & TVIS $_{\text {V }}$ ) & R VIS $^{(\%)}$ & AvIS $(\%)$ \\
\hline BZRGW & 20 & 20 & 60 \\
GRGW & 30 & 34 & 36 \\
GrRGW & 8 & 6 & 86 \\
OPBRGW & 26 & 24 & 51 \\
SPBRGW & 25 & 10 & 65 \\
GLDRGW & 36 & 51 & 13 \\
\hline
\end{tabular}

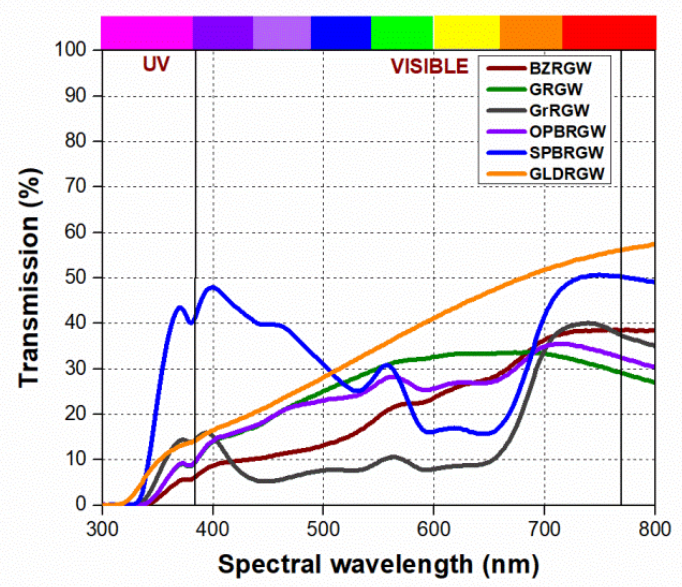

Figure 3. Spectral transmission of reflective glass windows in ultra violet and visible zone

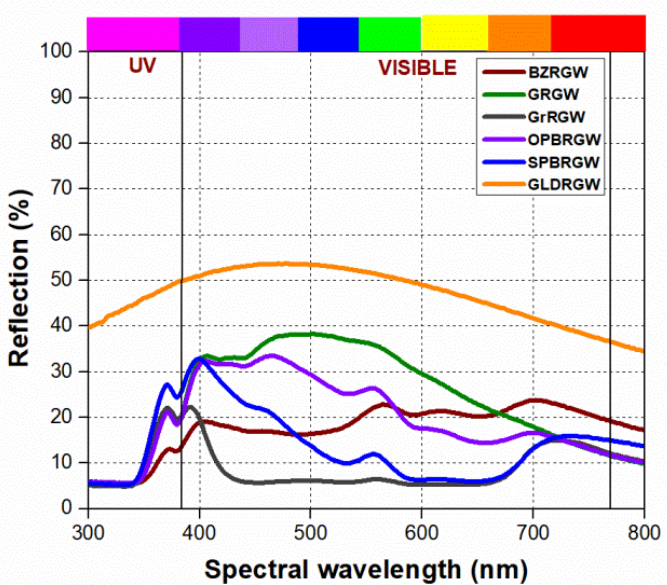

Figure 4. Spectral reflection of reflective glass windows in ultra violet and visible zone

Fig. 5 and Fig. 6 Illustrate the spectral characteristics of six reflective glass windows in entire solar spectrum wavelength range from $300 \mathrm{~nm}$ to $2500 \mathrm{~nm}$. Another MATLAB code was used to find the solar optical properties of all glasses in total solar spectrum wavelength range i.e. from $300 \mathrm{~nm}$ to $2500 \mathrm{~nm}$ by using British and ISO standards, with the following equations (5) to (7). Solar optical properties will affect heating and cooling loads which in turn increase energy consumption in buildings. These properties are used to find the heat gain in buildings through glass windows and these values are listed Table 2 .

$\mathrm{T}_{\text {Solar }}=\frac{\sum_{\lambda=300 \mathrm{~nm}}^{\lambda=2500 \mathrm{~nm}} \mathrm{~S}_{\lambda} \tau(\lambda) \Delta \lambda}{\sum_{\lambda=300 \mathrm{~nm}}^{\lambda=250 \mathrm{~nm}} \mathrm{~S}_{\lambda} \Delta \lambda}$

$\mathrm{R}_{\text {Solar }}=\frac{\sum_{\lambda=300 \mathrm{~nm}}^{\lambda=2500 \mathrm{~nm}} \mathrm{~S}_{\lambda} \rho(\lambda) \Delta \lambda}{\sum_{\lambda=300 \mathrm{~nm}}^{\lambda=2500 \mathrm{~nm}} \mathrm{~S}_{\lambda} \Delta \lambda}$

Absorbance of the window glass can be calculated by with this correlation. 
$\mathrm{A}_{\text {Solar }}=100-\mathrm{T}_{\text {Solar }}-\mathrm{R}_{\text {Solar }}$

Table 2. Solar optical properties of reflective glasses of thickness $5 \mathrm{~mm}$

\begin{tabular}{cccc}
\hline & \multicolumn{3}{c}{ Solar optical properties } \\
\hline Window glass & TSolar (\%) & RSolar $(\%)$ & Asolar (\%) \\
\hline BZRGW & 37 & 14 & 49 \\
GRGW & 29 & 14 & 57 \\
GrRGW & 26 & 8 & 66 \\
OPBRGW & 29 & 13 & 58 \\
SPBRGW & 42 & 11 & 47 \\
GLDRGW & 55 & 32 & 13 \\
\hline
\end{tabular}

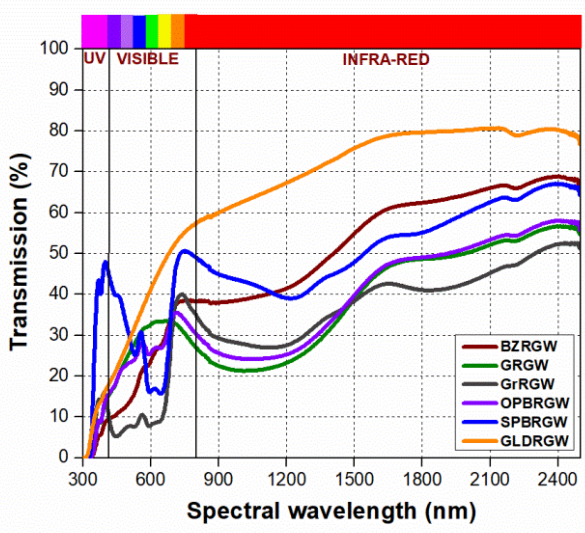

Figure 5. Spectral transmission of reflective glass windows in entire solar spectrum zone

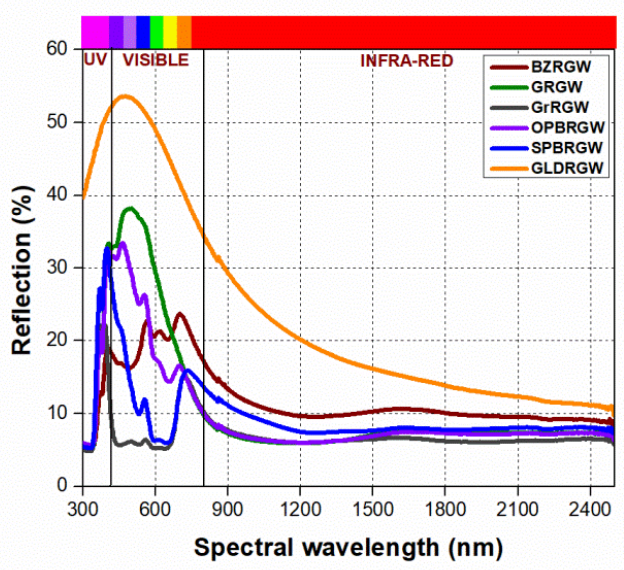

Figure 6. Spectral reflection of reflective glass windows in entire solar spectrum zone

\section{DESIGN AND THERMAL ANALYSIS PROCEDURE}

In this present paper class room model was designed with $3.5 \mathrm{~m} \times 3.5 \mathrm{~m} \times 3.5 \mathrm{~m}$ measurements by using design builder 4.7.0.027 software version tool. $40 \%$ window to wall ratio was measured as per Indian standards [29, 30], window of dimensions $2.45 \mathrm{~m} \times 2 \mathrm{~m}$ is placed in all four locations of building and kept i.e. one reflective glass placed to outside atmosphere and other reflective glass kept inside atmosphere such as DGLDRGW to DBZRGW one after another like that total twenty four window glass combinations were analyzed to composite climate zone of Indore to find the heat gain and day lighting on hottest day (May. 15 ${ }^{\text {th }}$ ) and coolest day (Dec. 21 ${ }^{\text {st }}$ ) as per Indian standards [31, 32]. As per Indian standards for class room buildings suggested daylight factor is in between
$1.9 \%$ to $3.8 \%$. To find the average daylight factor results inside the building were computed at a height of $0.75 \mathrm{~m}$ from the floor using Radiosity technique as per International Commission on Illumination standards (CIE Standards) at clear and Intermediate days from morning 9:00 A.M to evening 16:00 P.M with Energy plus 8.1.0.009 simulation version tool. Fig. 7 shows double reflective window glass combinations from DGLDRGW to DBZRGW.
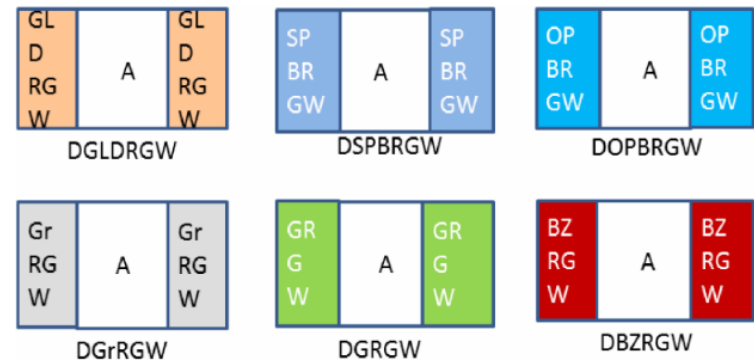

Figure 7. Double reflective window glasses from DGLDRGW to DBZRGW

\section{RESULTS AND DISCUSSIONS}

4.1 Heat gain in buildings through various double reflective window glass combinations of Indore climatic zone in hottest and coolest days

Fig. 8 and Fig. 9 present the heat gain in buildings through six double reflective window glass combinations from DWGC1 to DWGC6 through four locations of Indore ("22 ${ }^{\circ} .72^{\prime}$ $\left.\mathrm{N} 75^{\circ} .80^{\prime} \mathrm{E}^{\prime \prime}\right)$ climatic zone on hottest and coolest days were selected as per Indian standards. From the graphs it is evidently experiential that the heat gain in buildings through all double reflective window glass combinations from west location is more and less in south location on hottest day, and also evidently experiential that the heat gain in buildings from south location is more and less in north location on coolest days [34]. In hottest day, from south location double grey reflective window glass combination (DGrRGW) gains less heat $0.31 \mathrm{kWh}$ as shown in Fig. 8 and on coolest day double gold reflective window glass combination (DGLDRGW) gains more heat $8.55 \mathrm{kWh}$ as shown in Fig. 9 when compared with other reflective window glass combinations and compare to other locations.

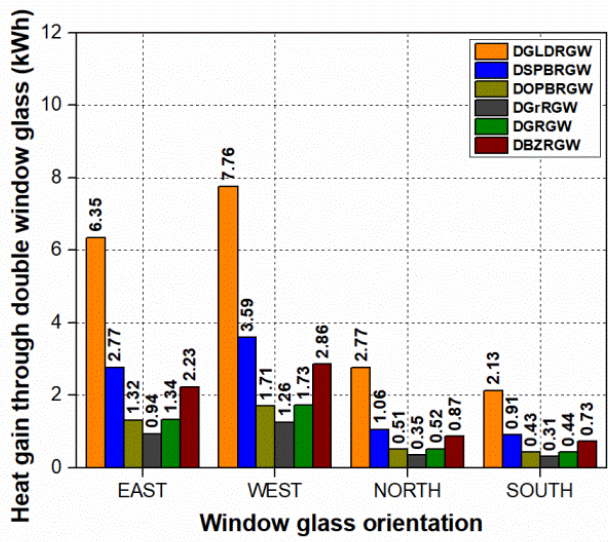

Figure 8. Heat gain into buildings through different reflective window glasses on hottest day 


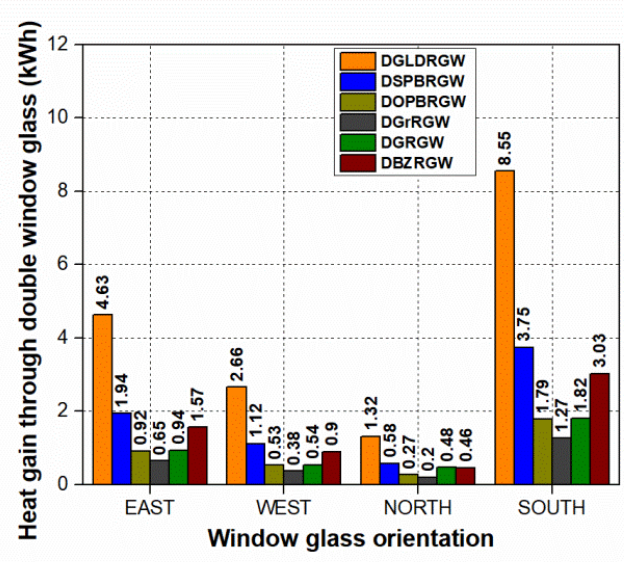

Figure 9. Heat gain into buildings through different reflective window glasses on coolest day

Day light factor simulation results of Varanasi climatic zone obtained from the Energy plus 8.1.0.009 version tool are compared with Madhusudan et.al (2015) experimental results and they are listed in table 3 and table 4 . The deviation of simulation results is less than $1 \%$. Therefore the simulation software tool is reliable and it can be used for computation of day light factor in buildings through various glasses.

Table 3. Day light factor simulation values compare with Madu sudan et al (2015) experimental results of Varanasi climatic zone ("25 $\left.25^{0} .28^{\prime} \mathrm{N}, 82^{0} .95^{\prime} \mathrm{E} "\right)$ in east location window at June $8^{\text {th }}$ in summer at clear sky conditions [14]

\begin{tabular}{|c|c|c|c|}
\hline \multirow[b]{2}{*}{$\begin{array}{l}\text { Time } \\
(\mathrm{Hrs})\end{array}$} & \multicolumn{3}{|c|}{ 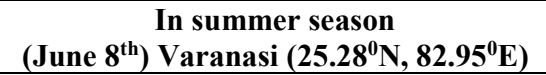 } \\
\hline & $\begin{array}{l}\text { Experimental } \\
\text { results }\end{array}$ & $\begin{array}{l}\text { Simulation } \\
\text { results }\end{array}$ & $\begin{array}{c}\text { Deviation } \\
(\%)\end{array}$ \\
\hline $8: 00$ & 3.3 & 3.4 & -0.03 \\
\hline 9:00 & 2.8 & 2.9 & -0.03 \\
\hline 10:00 & 2.6 & 2.4 & -0.07 \\
\hline 11:00 & 2.4 & 2.3 & -0.04 \\
\hline $12: 00$ & 2.1 & 1.9 & 0.09 \\
\hline 13:00 & 1.7 & 1.6 & 0.06 \\
\hline 14:00 & 1.4 & 1.2 & 0.07 \\
\hline $15: 00$ & 0.9 & 1.1 & 0.22 \\
\hline $16: 00$ & 0.6 & 0.7 & -0.17 \\
\hline $17: 00$ & 0.4 & 0.5 & -0.25 \\
\hline
\end{tabular}

Table 4. Day light factor simulation values compare with Madu sudan et al (2015) experimental results of Varanasi climatic zone (" $\left.25^{0} .28^{\prime} \mathrm{N}, 82^{\circ} .95^{\prime} \mathrm{E}^{\prime \prime}\right)$ in east location window at Jan $25^{\text {th }}$ in winter at intermediate sky conditions [14]

\begin{tabular}{cccc}
\hline & \multicolumn{3}{c}{ In winter season } \\
& (June 8 $\mathbf{8}^{\text {th }}$ ) & Varanasi $\left(\mathbf{2 5 . 2 8} \mathbf{0} \mathbf{N}, \mathbf{8 2 . 9 5}^{\mathbf{0}} \mathbf{E}\right)$ \\
\hline Time & $\begin{array}{c}\text { Experimental } \\
\text { results }\end{array}$ & $\begin{array}{c}\text { Simulation } \\
\text { results }\end{array}$ & $\begin{array}{c}\text { Deviation } \\
(\%)\end{array}$ \\
\hline Hrs) & 2.6 & 2.8 & -0.07 \\
$8: 00$ & 2.5 & 2.6 & -0.04 \\
$9: 00$ & 2.3 & 2.5 & -0.08 \\
$10: 00$ & 2.1 & 2.0 & -0.05 \\
$11: 00$ & 1.8 & 1.6 & 0.11 \\
$12: 00$ & 1.5 & 1.3 & 0.13 \\
$13: 00$ & 1.3 & 1.2 & 0.07 \\
$14: 00$ & 1.1 & 1.1 & 0.00 \\
$15: 00$ & 0.8 & 0.9 & -0.13 \\
$16: 00$ & 0.6 & 0.7 & -0.17 \\
$17: 00$ & & & \\
\hline
\end{tabular}

4.2 Average daylight factor in buildings through double gold reflective window glass (DGLDRGW) from all locations

Fig. 10 Illustrates the average daylight factor in a building from double gold reflective glass window combination (DGLDRGW) is placed in four locations of building on hottest and coolest days of Indore climatic zone. Fig. 10 Illustrates that average daylight factor is decline with rising time in both hottest and coolest days from east location window and also illustrates that the average daylight factor is raises with rising time in both hottest and coolest days from west location window. From north location window, average daylight factor is intermittent during hottest day and on coolest day, it looks like reverse hyperbola as shown in Fig. 10 due to lower solar insolation outside the atmosphere at specific day and time. From south location window, average daylight factor is intermittent during hottest day and on coolest day, it looks like inverted parabola as shown in Fig. 10 due to more solar insolation outside the atmosphere at specific day and time.

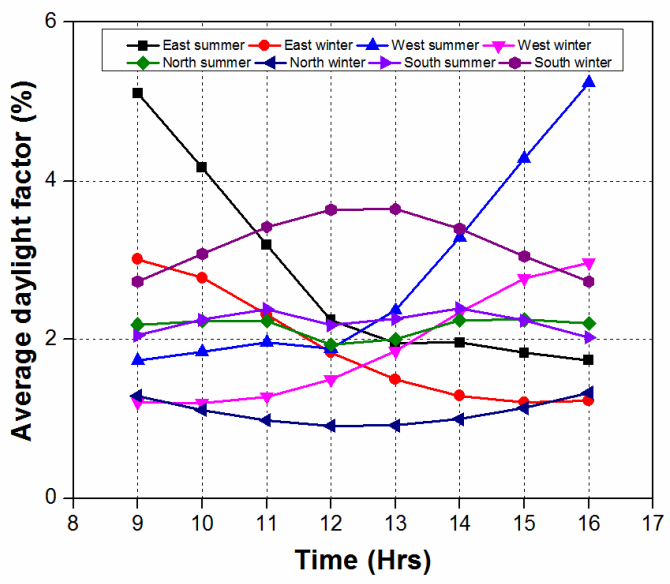

Figure 10. Average day light factor in buildings from double gold reflective window glass combination in all four locations

\subsection{Average daylight factor in buildings through double sapphire blue reflective window glass (DSPBRGW) from all locations}

Fig. 11 Illustrates the average daylight factor in a building from double sapphire blue reflective glass window combination (DSPBRGW) is placed in four locations of building on hottest and coolest days of Indore climatic zone. Fig. 11 Illustrates that average daylight factor declines with rising time in both hottest and coolest days from east location window and also illustrates that the average daylight factor raises with rising time in both hottest and coolest days from west location window. From north location window, average daylight factor is intermittent during hottest day and on coolest day, it looks like reverse hyperbola as shown in Fig 11 due to lower solar insolation outside the atmosphere at specific day and time. From south location window, average daylight factor is intermittent during hottest day and on coolest day, it looks like inverted parabola as shown in Fig 11 due to more solar insolation outside the atmosphere at specific day and time. 


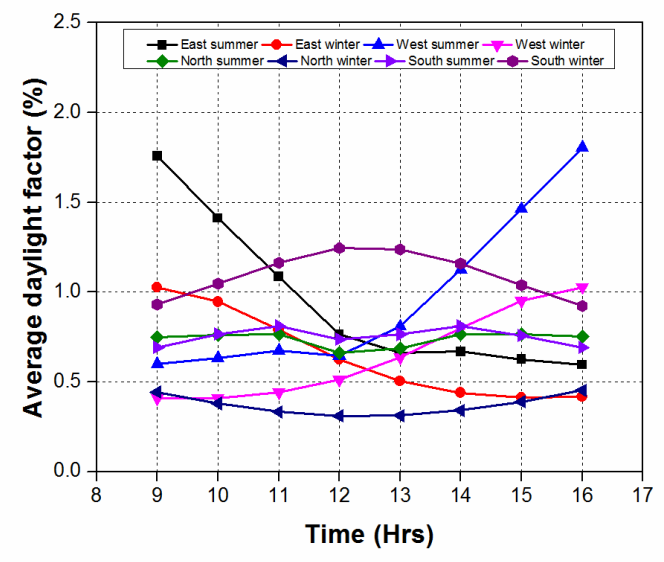

Figure 11. Average day light factor in buildings from double sapphire blue reflective window glass in all four locations

\subsection{Average daylight factor in buildings through double opal blue reflective window glass (DOPBRGW) from all locations}

Fig. 12 Illustrates the average daylight factor in a building from double opal blue reflective glass window combination (DOPBRGW) is placed in four locations of building on hottest and coolest days of Indore climatic zone. Fig. 12 Illustrates that average daylight factor declines with rising time in both hottest and coolest days from east location window and also illustrates that the average daylight factor raises with rising time in both hottest and coolest days from west location window. From north location window, average daylight factor is intermittent during hottest day and on coolest day, it looks like reverse hyperbola as shown in Fig. 12 due to lower solar insolation outside the atmosphere at specific day and time. From south location window, average daylight factor is intermittent during hottest day and on coolest day, it looks like inverted parabola as shown in Fig. 12 due to more solar insolation outside the atmosphere at specific day and time.

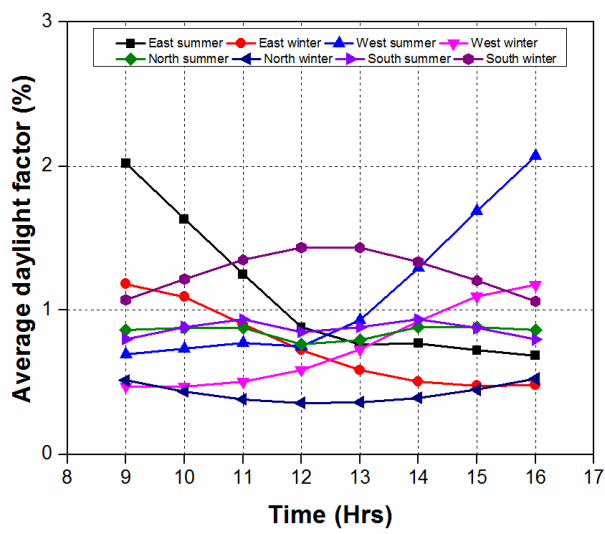

Figure 12. Average day light factor in buildings from double opal blue reflective window glass in all four locations

\subsection{Average daylight factor in buildings through double grey reflective window glass (DGrRGW) from all locations}

Fig. 13 Illustrates the average daylight factor in a building from double grey reflective glass window combination (DGrRGW) is placed in four locations of building on hottest and coolest days of Indore climatic zone. Fig. 13 Illustrates that average daylight factor declines with rising time in both hottest and coolest days from east location window and also illustrates that the average daylight factor raises with rising time in both hottest and coolest days from west location window. From north location window, average daylight factor is intermittent during hottest day and on coolest day, it looks like reverse hyperbola as shown in Fig. 13 due to lower solar insolation outside the atmosphere at specific day and time. From south location window, average daylight factor is intermittent during hottest day and on coolest day, it looks like inverted parabola as shown in Fig. 13 due to more solar insolation outside the atmosphere at specific day and time.

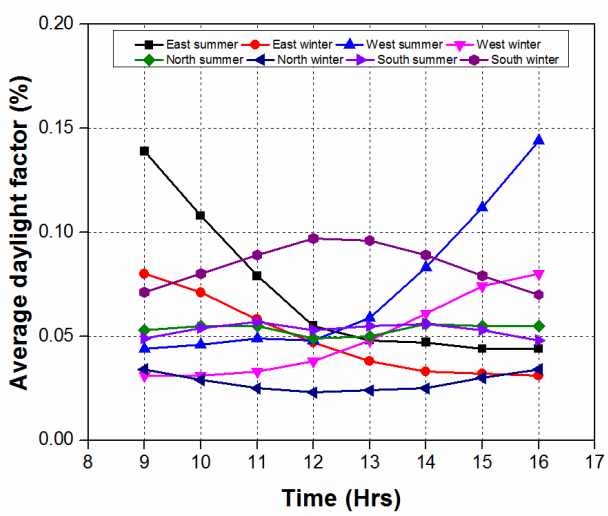

Figure 13. Average day light factor in buildings from double grey reflective window glass in all four locations

\subsection{Average daylight factor in buildings through double green reflective window glass (DGRGW) from all locations}

Fig. 14 Illustrates the average daylight factor in a building from double green reflective glass window combination (DGRGW) is placed in four locations of building on hottest and coolest days of Indore climatic zone. Fig. 14 Illustrates that average daylight factor declines with rising time in both hottest and coolest days from east location window and also illustrates that the average daylight factor is raises with rising time in both hottest and coolest days from west location window. From north location window, average daylight factor is intermittent during hottest day and on coolest day, it looks like reverse hyperbola as shown in Fig. 14 due to lower solar insolation outside the atmosphere at specific day and time. From south location window, average daylight factor is intermittent during hottest day and on coolest day, it looks like inverted parabola as shown in Fig. 14 due to more solar insolation outside the atmosphere at specific day and time.

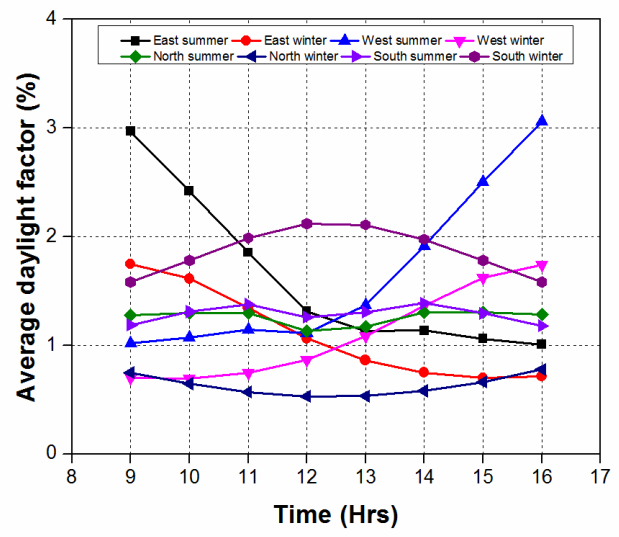

Figure 14. Average day light factor in buildings from double green reflective window glass in all four locations 


\subsection{Average daylight factor in buildings through double bronze reflective window glass (DBZRGW) from all locations}

Fig. 15 Illustrates the average daylight factor in a building from double bronze reflective glass window combination (DBZRGW) is placed in four locations of building on hottest and coolest days of Indore climatic zone. Fig. 15 Illustrates that average daylight factor declines with rising time in both hottest and coolest days from east location window and also illustrates that the average daylight factor raises with rising time in both hottest and coolest days from west location window. From north location window, average daylight factor is intermittent during hottest day and on coolest day, it looks like reverse hyperbola as shown in Fig. 15 due to lower solar insolation outside the atmosphere at specific day and time. From south location window, average daylight factor is intermittent during hottest day and on coolest day, it looks like inverted parabola as shown in Fig. 15 due to more solar insolation outside the atmosphere at specific day and time.

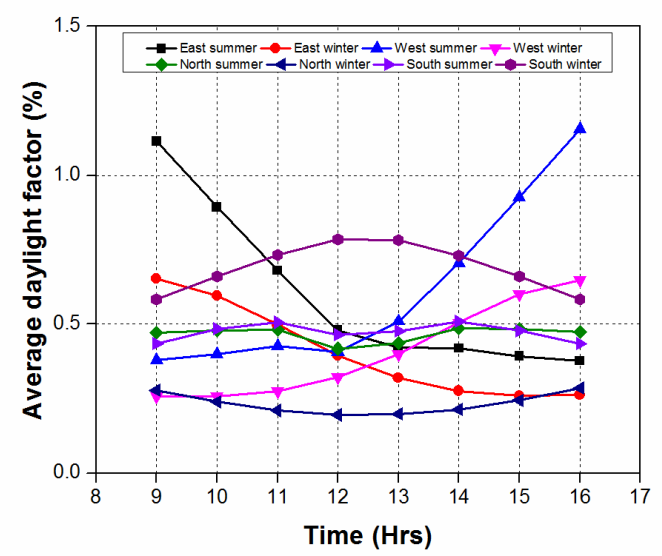

Figure 15. Average day light factor in buildings from double bronze reflective window glass in all four locations

\section{CONCLUSIONS}

This research paper reveals that there is reduction in the solar heat gain passing through various double reflective window glass combinations along with providing adequate daylight in School room buildings of Indore climatic region of India for both hottest and coolest days. This paper helps to reduce air-conditioning loads and cost of artificial daylighting in buildings.

- Heat gain through glass windows decreases with the double glazing layers due to reduced universal heat transfer coefficient.

- On peak summer day, double grey reflective window glass gain minimum heat of $0.31 \mathrm{kWh}$ due to reduced solar transmission property value of glass whereas on coolest day, double gold reflective window glass combination gains maximum heat of $8.55 \mathrm{kWh}$ due to increased solar transmission property value of glass.

- As far as both hottest and coolest days are concerned double gold reflective window glass (DGLDRGW) is found to be the best in the South orientation. During hottest day, DGLDRGW gains minimum heat of 2.13 $\mathrm{kWh}$ with adequate daylight factor $(2.049 \%$ at 9 A.M. and $2.025 \%$ at 4 P.M.) and also it gains maximum heat of $8.55 \mathrm{kWh}$ with adequate daylight factor $(2.729 \%$ at 9
A.M. and $2.732 \%$ at 4 P.M.) for school room building among six studied double reflective window glasses.

\section{REFERENCES}

[1] Singh I, Bansal NK. (2011). Thermal and optical properties of different window systems in India. International journal of Ambient Energy 23(4): 201-211. https://doi.org/10.1080/01430750.2002.9674891

[2] Kirankumar G, Ashok babu TP. (2015). Study of optimum inward glass tilt angle for window glass in different Indian latitudes to gain minimum heat into buildings. Energy Procedia 79: 1039-1045. https://doi.org/10.1016/j.egypro.2015.11.606

[3] Taleb AM, Al-Wattar AJH. (1988). Design of windows to reduce solar radiation transmittance into buildings. Solar \& Wind Technology 5: 503-515. https://doi.org/10.1016/0741-983X(88)90041-0

[4] Mohammed AF, Ismail MB. (2015). Energy performance of windows in office buildings considering daylight integration and visual comfort in hot climates. Energy \& Buildings 108: 307-316. https://doi.org/10.1016/j.enbuild.2015.09.024

[5] Kirankumar G, Saboor S, Ashok Babu TP. (2016). Simulation of various wall and window glass material buildings for energy efficient building design. Key Engineering Materials 692: 9-16. https://doi.org/10.4028/kem.2016.11.564

[6] Seunghwan Y, Hakgeun J, Byung LA, Hyesim H, Donghyun S, Junghoon L, Cheol YJ. (2013). Thermal transmittance of window systems and effects on building heating energy use and energy efficiency ratings in South Korea. Energy \& Buildings 67: 236-244. https://doi.org/10.1016/j.enbuild.2013.08.005

[7] Xing S, Zhang X. (2010). Environmental performance optimization of window-wall ratio for different window type in hot summer and cold winter zone in China based on life cycle assessment. Energy \& Buildings 42: 198202. https://doi.org/ 10.1016/j.enbuild.2009.08.015

[8] Ingy El-D, Mohamed G. (2017). Retrofitting strategy for building envelopes to achieve energy efficiency. Alexandria Engineering Journal 56: 579-589. https://doi.org/10.1016/j.aej.2017.05.011

[9] Halil A. (2016). Dedayination of optimum window to external wall ratio for offices in a hot and humid climate. Sustainability 187(8): https://doi.org/10.3390/su8020187

[10] Soojung K, Puyan AZ, Sheryl SF, Thomas F, Belgin TC. (2016). Assessment of the impact of window size, position and location on building energy load using BIM. Procedia Engineering 145: 1424-1431. https://doi.org/10.1016/j.proeng.2016.04.179

[11] Kirankumar G, Ashok Babu TP. (2017). Study of various glass materials to provide adequate day lighting in office buildings of warm and humid climatic zone in India. Energy Procedia 109: 181-189. https://doi.org/10.1016/j.egypro.2017.03.090

[12] Madhu S, Tiwari GN. (2017). Day lighting and energy performance of a building for composite climate, An experimental study. Alexandria Engineering Journal 55: 3091-3100. https://doi.org/10.1016/j.aej.2016.08.014

[13] Qiaoxia Y, Meng L, Chang S, Daniel M, Uzzal HMd, Xiang Z. (2015). Impact analysis of window-wall ratio 
on heating and cooling energy consumption of residential buildings in hot summer and cold winter zone in China. Journal of Engineering, Hindawi 1-17. https://doi.org/10.1155/2015/538254

[14] Madhu S, Tiwari GN, Al-Helal IM. (2015) A daylight factor model under clear sky conditions for building: An experimental validation. Solar Energy 115: 379-389. https://doi.org/10.1016/j.solener.2015.03.002

[15] Athienitis AK, Tzempelikos A. (2002). A methodology for simulation of daylight room illuminance distribution and light dimming for a room with a controlled shading device. Solar Energy 72(4): 271-282. https://doi.org/10.1016/S0038-092X(02)00016-6

[16] Kirankumar G, Saboor S, Ashok Babu TP. (2018). Effect of various external shading devices on windows for minimum heat gain and adequate day lighting into buildings of hot and dry climatic zone in India. Matec Web of Conference 144: 1-12. https://doi.org/10.1051/matecconf/201814404008

[17] Ahmed Abdel MMA. (2013). Using simulation for studying the influence of horizontal shading device protrusion on the thermal performance of spaces in residential buildings. Alexandria Engineering Journal 52: 787-796. https://doi.org/10.1016/j.aej.2013.09.008

[18] Madhu S, Richard GM, Tiwari GN. (2017). ClimateBased Daylight Modeling (CBDM) for an atrium: An experimentally validated novel daylight performance. Solar Energy 158: 559-571. https://doi.org/10.1016/j.solener.2017.09.067

[19] Arvind C. (2014). Performance of skylight illuminance inside a dome shaped adobe house under composite climate at New Delhi (India) A typical zero energy passive house. Alexandria Engineering Journal 53: 1-17. https://doi.org/10.1016/j.aej.2014.01.006

[20] Danny HWLi, Gary HW, Cheung Chris CSL. (2006). A simplified procedure for determining indoor daylight illuminance using daylight coefficient concept. Building and Environment 41: 578-589. https://doi.org/10.1016/j.buildenv.2005.02.027

[21] Danny HWLi, Gary HW, Cheung KL, Cheung T, Lam NT. (2010). Determination of vertical daylight illuminance under non-overcast sky conditions. Building and Environment 45: 498-508. https://doi.org/10.1016/j.buildenv.2009.07.008

[22] Yeo BY, Woo RJ, Kwang HL. (2014). Window material day lighting performance assessment algorithm comparing radiosity and split-flux methods. Energies 7: 2362-2376. https://doi.org/10.3390/en7042362

[23] Kirankumar G, Saboor S, Vanish K, Kim KH. Ashok Babu TP. (2018). Experimental and theoretical studies of various solar control window glasses for the reduction of cooling and heating loads in buildings across different climatic regions. Energy \& Buildings 176: 326-336. https://doi:10.1016/j.enbuild.2018.05.054

[24] Kirankumar G, Saboor S, Ashok Babu TP. (2018). Thermal and cost analysis of float and various tinted double window glass configurations on heat gain into buildings of hot \& dry climatic zone in India. Energy International Journal of Heat and Technology 36(1): 252 260. https://doi.org/10.18280/ijht.360134

[25] ASTM E424 (1971). Test for Solar energy Transmittance and Reflectance (terrestrial) of sheet materials. Washington DC, USA, 1320-1326.

[26] BS EN: 410 (1998). Glass in Building-Dedayination of luminous and solar characteristics of the glazing. British Standards, 1-24.

[27] ISO 9050:2003(E). (2003). Glass in building Determination of light transmittance, solar direct transmittance, total solar energy transmittance, ultraviolet transmittance and related glazing factors.

[28] SP: 41 (1987). (S\&T) Handbook on functional Requirement of Buildings other than industrial buildings. Bureau of Indian Standards, India, 33-40.

[29] ECBC (2009). Energy conservation building code. Bureau of Energy Efficiency, New Delhi.

[30] GRIHA (2011). Green rating for integrated habitat assessment. Ministry of New and Renewable Energy, New Delhi, India.

[31] NBC (2005). National Building Code of India 2005, Section 1 Building and Services Lighting and Ventilation. Part 8, Bureau of Indian Standards, New Delhi, India.

[32] Mani A. (1982). Solar radiation over India. Allied Publishers Private limited, India.

[33] Huang XQ, Zhang DL, Zhang X. (2017). Experimental research on heat/mass transfer features of corrugated plate spray humidification air coolers. Chemical Engineering Transactions 62: 379-384. https://doi.org/10.3303/CET1762064

[34] Wang Q, Ren T, Sun Y, Xue Y, Fei W, Wang X. (2017). Thermal dynamic model and analysis of residential buildings. Chemical Engineering Transactions 61: 10571062. https://doi.org/10.3303/CET1761174

\section{NOMENCLATURE}

$\begin{array}{ll}\mathrm{E}_{\mathrm{i}} & \text { Indoor illuminance }(\%) \\ \mathrm{E}_{\mathrm{o}} & \text { Outdoor illuminance }(\%) \\ \mathrm{T}_{\mathrm{VIS}} & \text { Visible solar transmittance }(\%) \\ \mathrm{R}_{\text {VIS }} & \text { Visible solar reflectance }(\%) \\ \mathrm{A}_{\mathrm{VIS}} & \text { Visible solar absorbance }(\%) \\ \mathrm{T}_{\text {Solar }} & \text { Solar transmittance }(\%) \\ \mathrm{R}_{\text {Solar }} & \text { Solar reflectance }(\%) \\ \mathrm{R}_{\text {Solar }} & \text { Solar absorbance }(\%) \\ \mathrm{S}_{\lambda} & \text { Relative spectral distribution of the solar radiation } \\ \left(\mathrm{W} / \mathrm{m}^{2}\right) & \end{array}$

\section{Greek letters}

$\Delta \lambda \quad$ Wavelength interval (nm)

$\mathrm{D}_{\lambda} \quad$ Relative spectral distribution of illuminant D65

$\mathrm{V}(\lambda) \quad$ Spectral luminous efficiency for photopic vision

defining the standard observer for photometry

$\tau(\lambda) \quad$ Spectral transmittance $(\%)$

$\rho(\lambda) \quad$ Spectral reflectance $(\%)$

$\alpha(\lambda) \quad$ Spectral absorbance $(\%)$

\section{Subscripts}

$\begin{array}{ll}\text { UV } & \text { Ultra-violet } \\ \text { VIS } & \text { Visible region } \\ \text { NIR } & \text { Near infrared region } \\ \text { BZRGW } & \text { Bronze reflective glass window } \\ \text { GRGW } & \text { Green reflective glass window } \\ \text { GrRGW } & \text { Grey reflective glass window } \\ \text { OPBRGW } & \text { Opal blue reflective glass window } \\ \text { OPBRGW } & \text { Sapphire blue reflective glass window }\end{array}$


GLDRGW Gold reflective glass window

DGLDRGW GLDRGW-Air gap 10mm- GLDRGW

DSPBRGW SPBRGW-Air gap 10mm-SPBRGW

DOPBRGW OPBRGW-Air gap 10mm- OPBRGW
DGRGW GrRGW-Air gap 10mm- GrRGW

DGrRGW GRGW-Air gap 10mm- GRGW

DBZRGW BZRGW-Air gap 10mm- BZRGW 